Lightowler, H, Thondre, S, Holz, A and Theis, S

Replacement of glycaemic carbohydrates by inulin-type fructans from chicory (oligofructose, inulin) reduces the postprandial blood glucose and insulin response to foods: Report of two double-blind, randomized, controlled trials

Lightowler, H, Thondre, S, Holz, A and Theis, S () Replacement of glycaemic carbohydrates by inulin-type fructans from chicory (oligofructose, inulin) reduces the postprandial blood glucose and insulin response to foods: Report of two double-blind, randomized, controlled trials. European Journal of Nutrition

doi:

This version is available: https://radar.brookes.ac.uk/radar/items/fc475527-3873-4cf3-bda0-49032ef62979/1/

Available on RADAR: March 2017

Copyright $(C$ and Moral Rights are retained by the author(s) and/ or other copyright owners. A copy can be downloaded for personal non-commercial research or study, without prior permission or charge. This item cannot be reproduced or quoted extensively from without first obtaining permission in writing from the copyright holder(s). The content must not be changed in any way or sold commercially in any format or medium without the formal permission of the copyright holders.

This document is the post print version of the journal article. Some differences between the published version and this version may remain and you are advised to consult the published version if you wish to cite from it. 


\section{Replacement of glycaemic carbohydrates by inulin-type fructans from chicory (oligofructose, inulin) reduces the postprandial blood glucose and insulin response to foods: report of two double- blind, randomized, controlled trials}

Helen Lightowler, 1 ,

Phone $+44(0) 1865483245$

Email hlightowler@brookes.ac.uk

Sangeetha Thondre, 1

Anja Holz, 2

Stephan Theis, 2

${ }^{1}$ Functional Food Centre, Faculty of Health and Life Sciences, Oxford Brookes University, Gipsy Lane Campus, Headington, Oxford, OX3 0BP UK

2 BENEO-Institute, Wormser Straße 11, 67283 Obrigheim/Pfalz, Germany

\section{Abstract \\ Purpose}

Inulin-type fructans are recognized as prebiotic dietary fibres and classified as non-digestible carbohydrates that do not contribute to glycaemia. The aim of the present studies was to investigate the glycaemic response (GR) and insulinaemic response (IR) to foods in which sucrose was partially replaced by inulin or oligofructose from chicory.

AQ1

\section{Methods}

In a double-blind, randomized, controlled cross-over design, 40-42 healthy adults consumed a yogurt drink containing oligofructose or fruit jelly containing inulin and the respective full-sugar variants. Capillary blood 
glucose and insulin were measured in fasted participants and at 15, 30, 45, 60, 90, and $120 \mathrm{~min}$ after starting to drink/eat. For each test food, the incremental area under the curve (iAUC) for glucose and insulin was calculated and the GR and IR determined.

\section{Results}

Consumption of a yogurt drink with oligofructose which was $20 \%$ reduced in sugars significantly lowered the glycaemic response compared to the fullsugar reference $\left(\mathrm{iAUC}_{120 \mathrm{~min}} 31.9\right.$ and $37.3 \mathrm{mmol} / \mathrm{L} / \mathrm{min}$, respectively; $p<$ 0.05). A fruit jelly made with inulin and containing $30 \%$ less sugars than the full-sugar variant likewise resulted in a significantly reduced blood glucose response (iAUC ${ }_{120 \mathrm{~min}} 53.7$ and $63.7 \mathrm{mmol} / \mathrm{L} / \mathrm{min}$, respectively; $p<0.05$ ). In both studies, the postprandial insulin response was lowered in parallel $(p<$ $0.05)$. The reduction of postprandial glycaemia was positively correlated to the proportion of sugars replaced by inulin-type fructans $(p<0.001)$.

\section{Conclusions}

In conclusion, the studies confirmed that substitution of glycaemic sugars by inulin or oligofructose from chicory may be an effective strategy to reduce the postprandial blood glucose response to foods.

\section{Keywords}

Glycaemia

Insulin

Dietary fibre

Prebiotics

Sugar replacement

\section{Introduction}

The postprandial blood glucose response as well as the related hyperinsulinaemia and lipidaemia have been implicated in the cause of chronic metabolic diseases such as obesity, type 2 diabetes mellitus, and cardiovascular disease [ 1,2$]$. Oxidative stress, insulin resistance, and inflammation caused by elevated blood glucose levels might play an important role in the development of such chronic diseases. Prevention is thus of utmost importance in diabetic patients and high-risk subjects as well as in healthy individuals, and the modulation of postprandial blood glucose levels in everyday life is essential to 
reduce cardiovascular risk [1]. There is evidence that over the longer term, pronounced postprandial glycaemic spikes and large blood glucose fluctuations, as often elicited by modern high-glycaemic carbohydrate foods, might be even more important than an increase in fasting glucose levels $[3,4,5]$.

Inulin-type fructans (inulin, oligofructose) are fermentable dietary fibres that are composed of fructosyl units linked via $\beta(2-1)$ glycosidic bonds. Due to the $\beta$ configuration of the anomeric $\mathrm{C} 2$ in the fructose monomers, inulin-type fructans are resistant to hydrolysis by human digestive enzymes that are mostly specific for $\alpha$-glycosidic linkages [6]. Inulin and oligofructose (shorter chain inulin) derived from chicory are thus classified as 'non-digestible carbohydrates' that do not contribute to the glycaemic response after ingestion $[6,7,8]$. Hence, they can be used to replace glycaemic carbohydrates in foods and drinks to reduce the postprandial blood glucose response.

Owing to their technical and organoleptic properties, such as an absent aftertaste and a good stability during food processes, inulin-type fructans are often used in food products for enrichment with dietary fibre and/or to replace glycaemic carbohydrates, including sugars [9]. The beneficial effect of lowering the postprandial blood glucose response by substituting glycaemic carbohydrates with non-digestible chicory derived fructans has been confirmed by several research groups $[10,11,12]$. A corresponding health claim for inulin and oligofructose was also positively evaluated by the European Food Safety Authority [13] and recently granted by the European Commission [14].

The evidence from earlier studies examining pure carbohydrate solutions should be further strengthened by two human intervention studies conducted according to more recent standards and guidance documents for appropriate study designs to investigate effects on postprandial glycaemia in final and complex food products $[15,16]$.

A reduction in postprandial glycaemic responses may be considered a beneficial physiological effect, as long as postprandial insulin responses are not disproportionally increased [16]. The aim of the present studies was to investigate the effect of partially replacing glycaemic sugars in final and complex food products with the non-digestible dietary fibres inulin and oligofructose from chicory on postprandial blood glucose and insulin response.

\section{Methods}

Two human blood glucose response studies with oligofructose (study I) and inulin (study II) from chicory used in partial replacement of glycaemic sugars 
were conducted at the Functional Food Centre at Oxford Brookes University, each using a double-blind, randomized, controlled cross-over design.

\section{Participants}

For the studies, 40-42 healthy male and female adults aged 18-60 years were recruited from staff and students of Oxford Brookes University. Participants were excluded if they were pregnant or lactating, $<18$ or $>60$ years of age, BMI $\geq 30 \mathrm{~kg} / \mathrm{m}^{2}$, fasting blood glucose $>6.1 \mathrm{mmol} / \mathrm{L}$, any food allergy or intolerance, medication affecting glucose regulation, appetite, and/or digestion/absorption of nutrients, history of diabetes mellitus, use of antihyperglycaemic drugs or insulin, major medical or surgical event requiring hospitalization within the preceding 3 months, use of steroids, protease inhibitors, or antipsychotics. In addition, participants were excluded if they were unable to comply with experimental procedures and safety guidelines.

Ethical approval for both studies was obtained from the University Research Ethics Committee at Oxford Brookes University (UREC Registration No: 090392 for the glycaemic response studies and UREC Registration No: 080357 for the insulin response studies). Participants were given full details of the study protocol and the opportunity to ask questions. All participants gave written informed consent prior to participation.

\section{Test foods}

\section{Study I}

A yogurt drink containing oligofructose from chicory (Orafti ${ }^{\circledR}$ P95) instead of sucrose was compared with a full-sugar reference yogurt drink. Both yogurt drinks had identical macronutrient composition except for a $20 \%$ replacement of glycaemic sugars with oligofructose (Table 1). The yogurt drinks had comparable taste and appearance and were provided in 250 -g portions.

\section{Table 1}

Composition of test foods

\begin{tabular}{|l|l|l|l|l|}
\hline & \multicolumn{2}{l|}{ Study I (yogurt drinks) } & \multicolumn{2}{l|}{ Study II (fruit jellies) } \\
\hline & $\begin{array}{l}\text { Full-sugar } \\
\text { version }\end{array}$ & $\begin{array}{l}\text { Oligofructose } \\
\text { version }\end{array}$ & $\begin{array}{l}\text { Full-sugar } \\
\text { version }\end{array}$ & $\begin{array}{l}\text { Inulin } \\
\text { version }\end{array}$ \\
\hline Protein $(\mathrm{g})$ & 6.0 & 6.0 & 0.9 & 0.9 \\
\hline Fat $(\mathrm{g})$ & 0.3 & 0.3 & 0.3 & 0.3 \\
\hline Carbohydrates $(\mathrm{g})$ & 30.5 & 24.8 & 34.0 & 23.0 \\
\hline
\end{tabular}




\begin{tabular}{|c|c|c|c|c|}
\hline & \multicolumn{2}{|c|}{ Study I (yogurt drinks) } & \multicolumn{2}{|c|}{ Study II (fruit jellies) } \\
\hline & $\begin{array}{l}\text { Full-sugar } \\
\text { version }\end{array}$ & $\begin{array}{l}\text { Oligofructose } \\
\text { version }\end{array}$ & $\begin{array}{l}\text { Full-sugar } \\
\text { version }\end{array}$ & $\begin{array}{l}\text { Inulin } \\
\text { version }\end{array}$ \\
\hline Sugars (g) & 29.4 & 23.7 & 34.0 & 23.0 \\
\hline Dietary fibre (g) & 1.5 & 6.8 & 2.4 & 15.3 \\
\hline Fructans (g) & $<0.1$ & 5.6 & $<0.1$ & 13.0 \\
\hline $\begin{array}{l}\text { Energy value } \\
{[\text { Kcal }(\mathrm{kJ})]}\end{array}$ & $148(620)$ & $135(565)$ & $142(596)$ & $124(520)$ \\
\hline \multicolumn{5}{|c|}{${ }^{a}$ Values are given as content per portion, i.e., per 250 -g yogurt drink } \\
\hline
\end{tabular}

\section{Study II}

A fruit jelly containing inulin from chicory (Orafti ${ }^{\circledR} \mathrm{GR}$ ) instead of sucrose was compared with a full-sugar reference fruit jelly. Both fruit jelly preparations had identical macronutrient composition except that $30 \%$ of glycaemic sugars were replaced by inulin (Table 1 ). The fruit jellies had similar taste and appearance and were ingested in 110-g portions.

Oligofructose and inulin are widely used as a sugar substitute in foods such as ice cream, dairy products, and confectionary, without affecting sweetness and texture. All products were specially developed for the studies by BENEO $\mathrm{GmbH}$. Within each study, products were matched for taste, texture, and sweetness, and were provided as single encoded portions. All participants were asked to report any adverse events following consumption of the products to the researchers during the study.

\section{Study protocol}

In both studies, the glycaemic response method used by the Functional Food Centre at Oxford Brookes University was carried out in accordance with ISO standards [15].

On the day prior to a test, participants were asked to restrict their intake of alcohol and caffeine-containing drinks and participation in intense physical activity (e.g., long periods in the gym, excessive swimming, running, and aerobics). Participants were also told not to eat or drink after 9 p.m. the night before a test, although water was allowed in moderation. 
Participants were studied in the morning after a 12-h overnight fast. In both studies, participants consumed the test foods and reference foods at a comfortable pace, within 5-10 min, and remained sedentary during each session.

In both studies, the reference and test foods were tested once in random order, with at least a 1-day gap between measurements to minimize carry-over effects. The sequence of product intake was randomized using a computer-based random order generator (Department of Psychology, Oxford Brookes University). Both studies were carried out double-blind with researchers and participants blinded to the nature of the test and reference products. Decoding of the products was only done after completion of data collection and blind data review.

\section{Anthropometric measurements}

Anthropometric measurements were made in the fasting state prior to the first test in each of the two studies. Height was recorded to the nearest centimetre using a stadiometer (Seca Ltd., UK), with participants standing erect and without shoes. Body weight was recorded to the nearest $0.1 \mathrm{~kg}$, with participants wearing light clothing and no shoes. Body mass index (BMI) was calculated using the standard formula: weight $(\mathrm{kg}) /$ height $(\mathrm{m})^{2}$. Body fat percentage was measured using a body composition analyser (Tanita BC-418 MA; Tanita UK Ltd).

\section{Blood glucose measurement}

Fasting blood samples were taken at -5 and 0 min before consumption of the test products and reference products and the baseline value taken as a mean of these two values. Products were consumed immediately after this and further blood samples were taken at $15,30,45,60,90$, and $120 \mathrm{~min}$ after starting to drink/eat.

Blood was obtained by finger-prick using the Unistik ${ }^{\circledR} 3$ single-use lancing device (Owen Mumford). The previous reports suggest that capillary rather than venous blood sampling is preferred for reliable GR testing [17]. Prior to a finger-prick, participants were encouraged to warm their hand to increase blood flow. Fingers were not squeezed to extract blood from the fingertip as this may dilute with plasma. Blood glucose was measured using the HemoCue Glucose $201+$ analyser $\left(\mathrm{HemoCue}^{\circledR}\right.$ Ltd), which was calibrated daily using control solution from the manufacturer.

The laboratory's coefficient of variation for 20 or more duplicate measurements of fasting glucose (i.e., minute-to-minute variation in human participants) was $<5 \%$. The inter-assay coefficient of variation (i.e., analytical variation) on standard solutions was $<3.6 \%$. 


\section{Insulin measurements}

The same puncture site and time points were used for sampling blood for both glucose and insulin. For each insulin measurement, $300 \mu \mathrm{L}$ of capillary blood was obtained and collected into chilled microvette ${ }^{\circledR}$ capillary blood collection tubes treated with di Pottasium EDTA (CB 300 K2E; Sarstedt Ltd.). The microvette ${ }^{\circledR}$ tubes were centrifuged and $200 \mu \mathrm{L}$ of the supernatant plasma obtained. Insulin concentrations in the plasma samples were determined by electrochemiluminescence immunoassay using an automated analyzer (Cobas ${ }^{\circledR}$ E411; Roche diagnostics). The Cobas ${ }^{\circledR}$ system is a reliable method of plasma insulin determination [18].

\section{Main study outcomes}

Both studies were designed to detect differences in the incremental area under the blood glucose response curve (glucose iAUC) as the primary outcome parameter. Secondary outcomes of both studies comprised differences in insulin iAUC and peak blood glucose and insulin concentrations.

\section{Sample size calculation}

Sample size calculation for both studies was based on published GI data of fullsugar and sugar-reduced versions of dairy products [19]. To detect a reduction in postprandial glycaemia with a two-sided $\alpha$-level of $5 \%$ and a power of $80 \%$, a sample size of at least 35 participants was necessary. To account for any dropouts, 40-42 participants were recruited for the studies.

\section{Statistical analysis}

In both studies, data were analysed using the IBM Statistical Package SPSS version 19.0 (SPSS Inc., Chicago, Illinois). Prior to statistical analysis, the normality of the data was tested using the Shapiro-Wilk test. Tests for paired samples (paired $t$ test for normally distributed data and Wilcoxon matched-pairs signed rank test for not normally distributed data) were used to compare the peak and iAUC values of blood glucose and insulin between the reference product and test product. If not indicated otherwise, data are presented as mean \pm standard error of the mean (SEM). Pearson's correlation was used to determine if a linear relationship exists between the percentage of glycaemic sugars replaced by inulin-type fructans and the percentage reduction of blood glucose response. Statistical significance was set at $p<0.05$ (two-sided).

\section{Results}

Study I: yogurt drink with oligofructose 
Initially, 40 participants were recruited, of which one dropped out before collecting any data due to time commitments. Hence, 39 participants completed the study and are included in the statistical analysis. Baseline characteristics of participants are shown in Table 2 .

\section{Table 2}

Baseline characteristics of participants (mean \pm SD)

\begin{tabular}{|l|l|l|}
\hline Parameter & Study I $(\boldsymbol{N}=\mathbf{3 9})$ & Study II $(\boldsymbol{N}=\mathbf{4 2})$ \\
\hline Male/female & $13 / 26$ & $16 / 26$ \\
\hline Age (years) & $2626.0 \pm 8.2$ & $26.2 \pm 7.0$ \\
\hline Height $(\mathrm{m})$ & $1.71 \pm 0.07$ & $1.72 \pm 0.09$ \\
\hline Weight $(\mathrm{kg})$ & $6767.0 \pm 12.0$ & $67.3 \pm 13.2$ \\
\hline BMI $\left(\mathrm{kg} / \mathrm{m}^{2}\right)$ & $22.3 \pm 4.6$ & $22.6 \pm 2.7$ \\
\hline Fat mass $(\%)$ & $2424.0 \pm 8.4$ & $22.2 \pm 8.2$ \\
\hline Lean body mass $(\mathrm{kg})$ & $51.0 \pm 10.6$ & $52.7 \pm 12.0$ \\
\hline
\end{tabular}

Blood glucose and insulin response curves are shown in Fig. 1. The glucose iAUC $_{120 \text { min }}$ was significantly lower after consumption of the yogurt drink with oligofructose compared to the full-sugar reference variant $(-14 \%, p<0.05$;

Table 3 ). Likewise, the peak blood glucose concentration following ingestion of the yogurt drink with oligofructose was significantly lower $(p<0.05$; Table 3$)$. In parallel, insulin iAUC ${ }_{120 \min }(p<0.01$; Table 3$)$ and peak insulin concentration (n.s.) were lower following ingestion of the oligofructosecontaining yogurt drink. Both product variants were accepted and tolerated well, and there were no adverse events during the course of the study.

\section{Fig. 1}

Blood glucose (a) and insulin response (b) to yogurt drink variants (means $\pm \mathrm{SEM}$, $N=39$ ) 


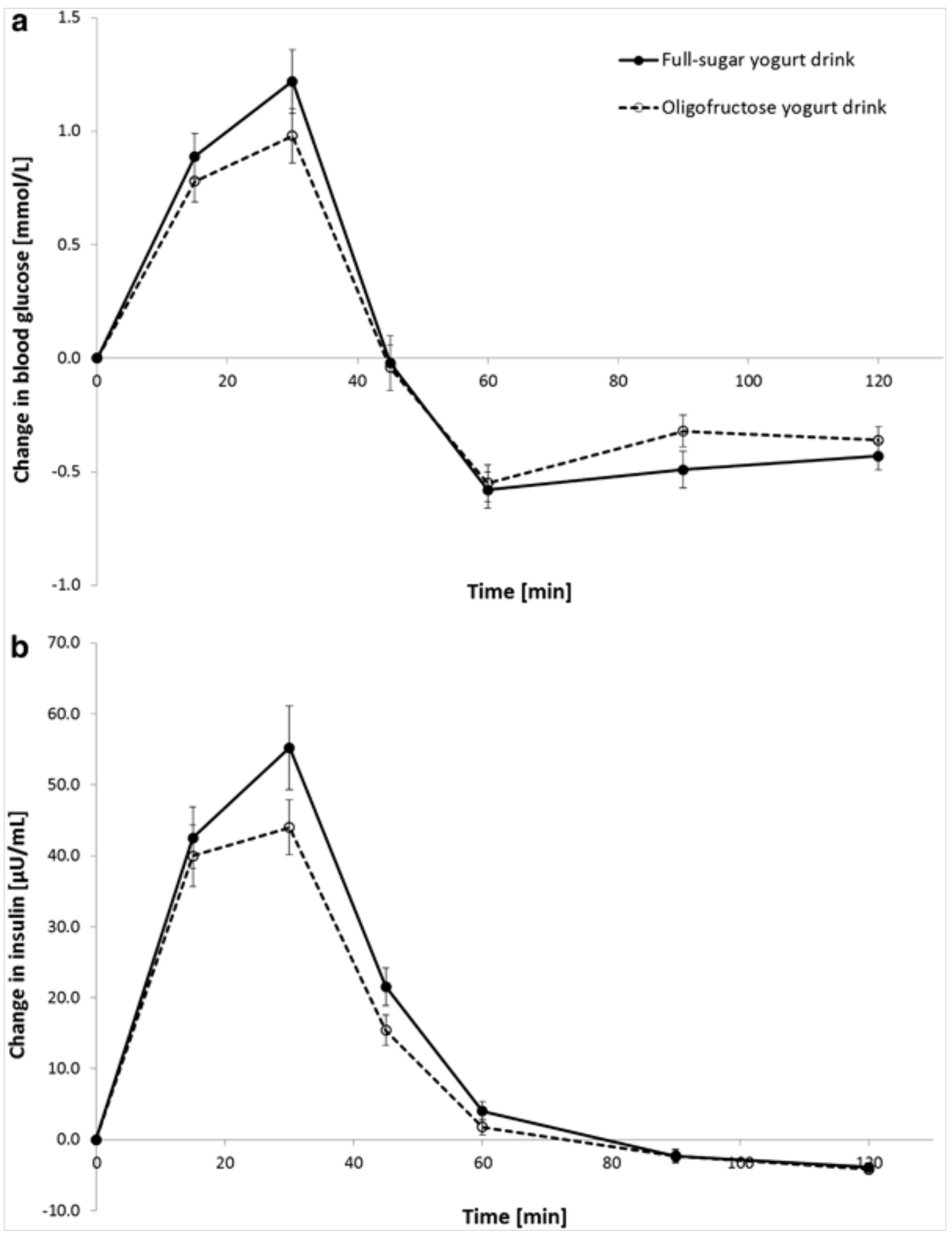

Table 3

Results of study I (yogurt drinks)

\begin{tabular}{|c|c|c|c|c|}
\hline & \multicolumn{2}{|l|}{ Blood glucose ${ }^{a}$} & \multicolumn{2}{|l|}{ Insulin ${ }^{a}$} \\
\hline & $\begin{array}{l}\mathrm{iACC}_{120 \min } \\
(\mathrm{mmol} / \mathrm{L} / \mathrm{min})\end{array}$ & $\begin{array}{l}\text { Peak } \\
(\mathrm{mmol} / \mathrm{L})\end{array}$ & $\begin{array}{l}\text { iAUC }_{120 \min } \\
(\mu \mathrm{U} / \mathrm{mL} / \mathrm{min})\end{array}$ & $\begin{array}{l}\text { Peak } \\
(\mu \mathrm{U} / \mathrm{mL})\end{array}$ \\
\hline $\begin{array}{l}\text { Full-sugar } \\
\text { version }\end{array}$ & $37.3 \pm 3.0$ & $6.3 \pm 0.1$ & $1924.9 \pm 144.6$ & $75.8 \pm 6.1$ \\
\hline
\end{tabular}




\begin{tabular}{|c|c|c|c|c|}
\hline & \multicolumn{2}{|l|}{ Blood glucose } & \multicolumn{2}{|l|}{ Insulin } \\
\hline & $\begin{array}{l}\text { iAUC } \\
(\mathbf{m m o l} / \mathbf{L} / \mathbf{m i n})\end{array}$ & $\begin{array}{l}\text { Peak } \\
(\mathbf{m m o l} / \mathrm{L})\end{array}$ & $\begin{array}{l}\text { iAUC } \\
(\mu \mathrm{U} / \mathrm{mL} / \mathrm{min})\end{array}$ & $\begin{array}{l}\text { Peak } \\
(\mu \mathrm{U} / \mathbf{m L})\end{array}$ \\
\hline $\begin{array}{l}\text { Oligofructose } \\
\text { version }\end{array}$ & $31.9 \pm 3.2$ & $6.0 \pm 0.1$ & $1598.2 \pm 115.0$ & $68.2 \pm 4.3$ \\
\hline$p$ value & $0.02 *$ & $0.029 *$ & $0.007 *$ & 0.151 \\
\hline \multicolumn{5}{|c|}{$* p$ value considered statistically significant } \\
\hline \multicolumn{5}{|c|}{$\begin{array}{l}\text { a Results for blood glucose and insulin measurements are means } \pm \text { SEM of } 39 \\
\text { participants }\end{array}$} \\
\hline
\end{tabular}

\section{Study II: fruit jelly with inulin}

Forty-two participants completed the study. Due to an equipment error, insulin data from three participants could not be analysed. Hence, the presented blood glucose data are means of 42 participants' results and insulin data are reported as means of 39 participants. Baseline characteristics of participants are shown in Table 2 .

Blood glucose and insulin response curves are depicted in Fig. 2. The glucose iAUC $_{120 \text { min }}$ was significantly lower after consumption of the fruit jelly with inulin as compared to the full-sugar reference version $(-16 \%, p<0.05$; Table 4$)$. Peak blood glucose concentration was likewise significantly lower after consumption of the inulin-containing fruit jelly $(p<0.05$; Table 4$)$. In parallel, insulin $\mathrm{iAUC}_{120 \mathrm{~min}}$ and peak insulin concentration were significantly lower following ingestion of the fruit jelly with inulin (both $p<0.001$; Table 4 ). Both product variants were accepted and tolerated well, and there were no adverse events during the course of the study.

\section{Fig. 2}

Blood glucose (a) and insulin response (b) to fruit jelly variants (means $\pm \mathrm{SEM}, N$ $=42$ for glucose, $N=39$ for insulin) 


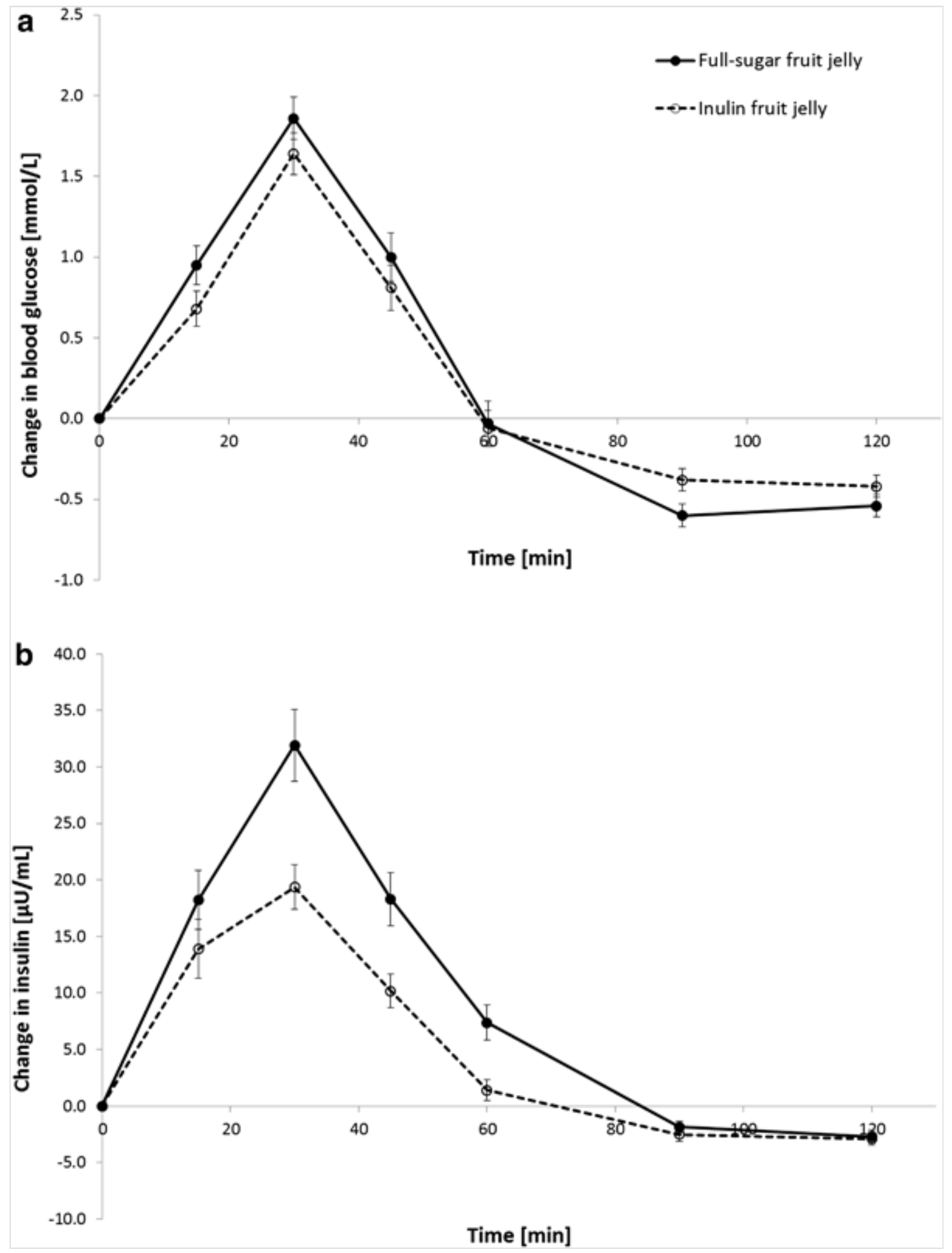

\section{Table 4}

Results of study II (fruit jellies)

\begin{tabular}{|l|l|l|l|}
\hline & \multicolumn{2}{|l|}{ Blood glucose $^{\mathbf{a}}$} & \multicolumn{2}{l}{ Insulin $^{\mathbf{b}}$} \\
\hline $\begin{array}{l}\text { iAUC } 120 \mathrm{~min} \\
(\mathrm{mmol} / \mathrm{L} / \mathrm{min})\end{array}$ & $\begin{array}{l}\text { Peak } \\
(\mathrm{mmol} / \mathrm{L})\end{array}$ & $\begin{array}{l}\text { iAUC } \\
(\mu \mathrm{U} / \mathrm{mL} / \mathrm{min})\end{array}$ & $\begin{array}{l}\text { Peak } \\
(\mu \mathrm{U} / \mathrm{mL})\end{array}$ \\
\hline
\end{tabular}




\begin{tabular}{|c|c|c|c|c|}
\hline \multirow[b]{2}{*}{$\begin{array}{l}\text { Full-sugar } \\
\text { version }\end{array}$} & \multicolumn{2}{|c|}{ Blood glucose } & \multicolumn{2}{|l|}{ Insulin } \\
\hline & $63.7 \pm 4.7$ & $6.7 \pm 0.12$ & $1201.1 \pm 100.0$ & $45.2 \pm 3.7$ \\
\hline $\begin{array}{l}\text { Inulin } \\
\text { version }\end{array}$ & $53.7 \pm 4.8$ & $6.4 \pm 0.12$ & $725.7 \pm 65.7$ & $32.7 \pm 2.6$ \\
\hline$p$ value & $0.045^{*}$ & $0.010 *$ & $<0.001 *$ & $<0.001 *$ \\
\hline \multicolumn{5}{|c|}{${ }^{\text {a}}$ Results for blood glucose measurements are means \pm SEM of 42 participants } \\
\hline \multicolumn{5}{|c|}{${ }^{b}$ Results for insulin measurements are means \pm SEM of 39 participants } \\
\hline \multicolumn{5}{|c|}{$* p$ value considered statistically significant } \\
\hline
\end{tabular}

\section{Correlation between sugar replacement and reduction in postprandial blood glucose}

To identify further human intervention studies investigating the effect of inulintype fructans from chicory used in replacement of glycaemic sugars on the postprandial blood glucose response, a review of the literature was performed. Four studies reporting the results of in total seven blood glucose response trials were identified as being pertinent to the current research question $[10,11,12$, Hull et al. (unpublished report)].

The main findings of the above-mentioned studies as well as the current data are summarized in Table 5. The percentage of glycaemic sugars that have been replaced by chicory inulin or oligofructose was calculated in the same way as for the yogurt drink and fruit jelly tested in the present studies. All studies measured the postprandial glycaemic responses over $120 \mathrm{~min}$.

\section{Table 5}

Summary of data on the effect of chicory inulin-type fructans used in partial replacement of glycaemic sugars on the postprandial blood glucose response

\begin{tabular}{|l|l|l|l|}
\hline Reference & $\begin{array}{l}\text { Chicory } \\
\text { inulin-type } \\
\text { fructan }\end{array}$ & $\begin{array}{l}\text { Replacement of glycaemic } \\
\text { sugars by inulin-type } \\
\text { fructans }\end{array}$ & $\begin{array}{l}\text { Reduction of } \\
\text { postprandial blood } \\
\text { glucose response } \mathbf{6} \text { (\%) }\end{array}$ \\
\hline $\begin{array}{l}\text { Study I } \\
\text { (current } \\
\text { data) }\end{array}$ & Oligofructose & 20 & 14 \\
\hline $\begin{array}{l}\text { Study II } \\
\text { (current } \\
\text { data) }\end{array}$ & Inulin & 30 & 16 \\
\hline
\end{tabular}




\begin{tabular}{|c|c|c|c|}
\hline Reference & $\begin{array}{l}\text { Chicory } \\
\text { inulin-type } \\
\text { fructan }\end{array}$ & $\begin{array}{l}\text { Replacement of glycaemic } \\
\text { sugars by inulin-type } \\
\text { fructans }(\%)\end{array}$ & $\begin{array}{l}\text { Reduction of } \\
\text { postprandial blood } \\
\text { glucose response }(\%)\end{array}$ \\
\hline $\begin{array}{l}\text { Tarini and } \\
\text { Wolever } \\
{[10]}\end{array}$ & Inulin & 30 & 26 \\
\hline $\begin{array}{l}\text { Grysman et } \\
\text { al. [9] }\end{array}$ & Inulin & 30 & 32 \\
\hline Meyer [8] & Oligofructose & 60 & 52 \\
\hline $\begin{array}{l}\text { Hull et al } \\
\text { (unpublished } \\
\text { data) }\end{array}$ & Oligofructose & 74 & 65 \\
\hline Meyer [8] & Oligofructose & 85 & 80 \\
\hline Meyer [8] & Inulin & 90 & 86 \\
\hline Meyer [8] & Inulin & 99.5 & 95 \\
\hline \multicolumn{4}{|c|}{$\begin{array}{l}\text { a The percentage of sugars replacement was calculated based on a weight by weight } \\
\text { basis taking into account the actual inulin/oligofructose content of commercial } \\
\text { products }\end{array}$} \\
\hline
\end{tabular}

Analysis revealed that the relationship between the percentage of glycaemic sugars replaced by inulin-type fructans and the extent to which the postprandial blood glucose response was reduced could be described by a linear slope (Fig. 3$)$ with a statistically significant positive correlation $(r=0.990, p<0.001)$.

\section{Fig. 3}

Relationship between the percentage of sugars replaced by chicory inulin-type fructans and the reduction of the postprandial glycaemic response 


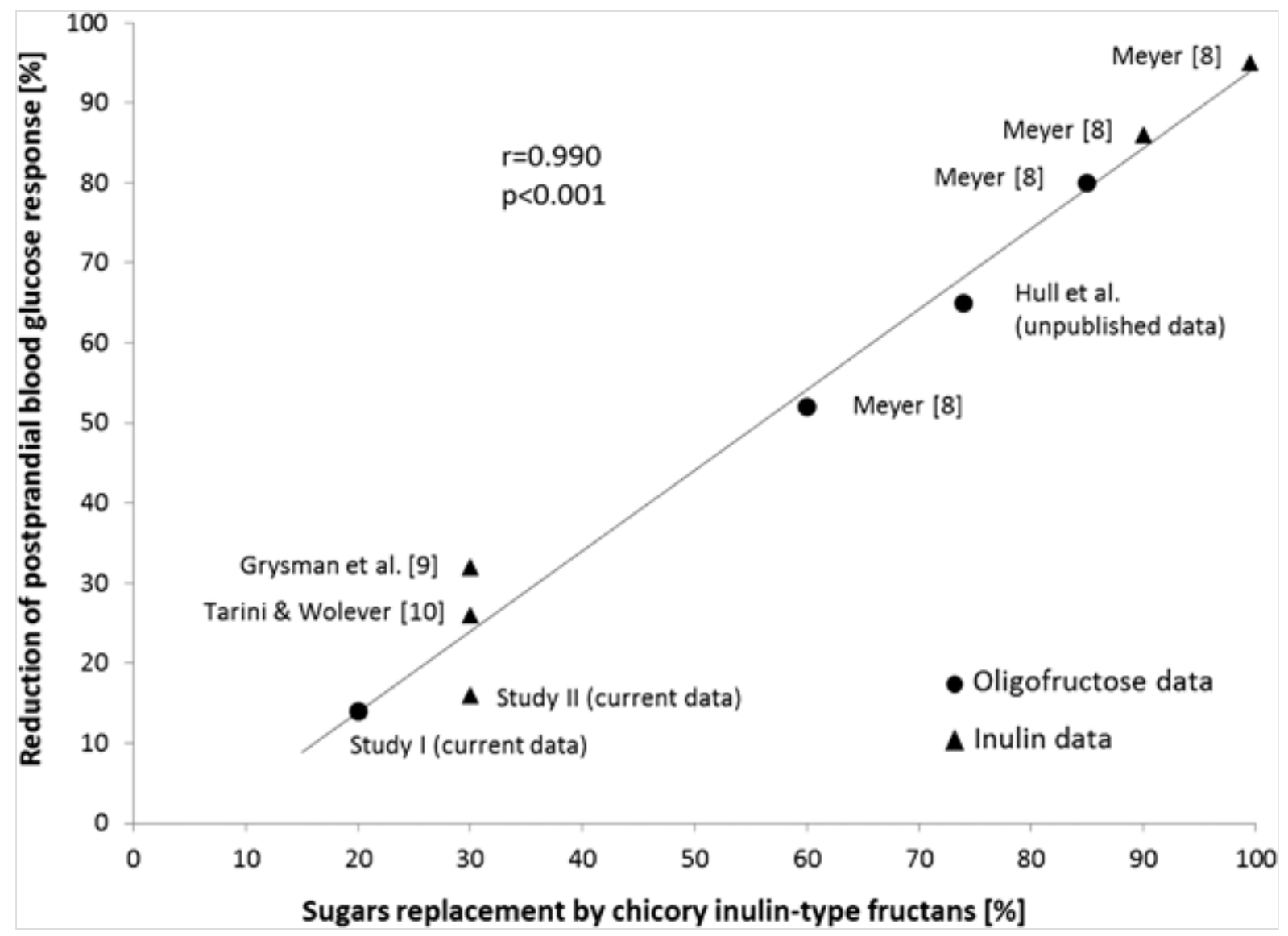

\section{Discussion}

The current studies have shown that chicory inulin-type fructans (oligofructose, inulin) are able to significantly reduce the postprandial glycaemic and insulinaemic response to foods and drinks when used in replacement of glycaemic sugars. The glucose iAUC as well as peak blood glucose concentrations were significantly lower compared to the respective full-sugar reference. Moreover, the attenuated postprandial glycaemia was shown to be accompanied by a significantly decreased insulin response. Lowering the postprandial blood glucose response to food products using chicory inulin or oligofructose instead of glycaemic sugars could contribute to prevention and reducing the risk of chronic metabolic diseases [1,2]. Importantly, based on the generally accepted suitability of oligofructose and inulin as sugar replacers in food products, this could be achieved without compromising taste and sensory qualities which is essential for their acceptance of lower-glycaemic food products at the consumer level and during everyday life.

Following a health claim application, the principle of lowering the postprandial glycaemic response to a food product by substituting glycaemic sugars with nondigestible inulin or oligofructose has been positively evaluated by the European Food Safety Authority [13] and the corresponding health claim was recently granted by the European Commission [14]. 
The findings of both blood glucose response studies reported here are in line with results of the previous human intervention studies examining the glycaemic response to foods or drinks in which glycaemic sugars have been (partially) substituted by inulin-type fructans from chicory [10,11,12]. The available data consistently show a reduction of the postprandial blood glucose response when inulin-type fructans are used to replace sugars in foods and drinks [11]. This effect refers to the non-digestibility of chicory inulin-type fructans in the human small intestine and the fact that they do not contribute to glycaemia after ingestion $[6,7,8]$.

Our studies have demonstrated a 14 and $16 \%$ reduction in glycaemic iAUC following consumption of the inulin-supplemented yogurt and fruit jellies, respectively. Similarly, the previous research has shown a $12 \%$ difference in postprandial glucose following consumption of a low-GI and high GI diet [20]. Moreover, levels of fructosamine and cholesterol were less when reductions in postprandial glycaemia of $29 \%$ were maintained over a period of 2 weeks in people with type 2 diabetes [21].

The significant positive correlation found between the percentage of sugars replaced by inulin-type fructans from chicory and the reduction of the postprandial blood glucose response demonstrates that the higher the proportion of sugars replaced by non-digestible chicory inulin-type fructans, the lower the postprandial blood glucose response to the food. This finding is anything but surprising, because the causal relationship is explained by the lower amount of available carbohydrates contained in the food product that could contribute to postprandial glycaemia $[22,23]$. Although this linear relationship is logical and perfectly obvious, this is, to the best of our knowledge, the first time that such correlation is reported. Based on this analysis, it can also be assumed that lower levels of sugar replacement by chicory inulin and oligofructose than the confirmed $20 \%$ may lead to a proportionately attenuated postprandial blood glucose response.

One of the strengths of the current studies is that they were well controlled. Specifically developed tests and reference products were used which were essentially identical in terms of macronutrient content except that sucrose was replaced by inulin or oligofructose on a weight by weight basis. This allowed the identification of the effect of replacing glycaemic sugars by inulin-type fructans without confounding factors. Both studies were conducted according to current ISO standards [15] and fulfilling EFSA's requirements for appropriate study designs for blood glucose response trials [16]. By assessing insulin concentrations in parallel to blood glucose levels, the results showed that the reduced-sugars variants containing inulin or oligofructose from chicory do not 
lead to a disproportionally increased insulin response (rather they lowered the insulinaemic response as well). This is considered an important aspect to be accepted as a beneficial physiological effect by regulatory authorities $[13,16]$. Furthermore, the current studies examined the blood glucose response to yogurt drinks and fruit jellies and thus realistic product formulations rather than only sugary solutions. The portion sizes tested were with 250-g yogurt drink and 110$\mathrm{g}$ fruit jelly realistic in view of the typical serving sizes for such products. Hence, the results clearly demonstrate that the effect of lowering the postprandial glycaemic response to foods and drinks by replacing glycaemic sugars with non-digestible inulin-type fructans is confirmed for final food products consumed in realistic amounts. Thus, the effect is relevant at the consumer level and for everyday life.

Most importantly, the current studies showed a significantly reduced blood glucose response with a sugars replacement by inulin-type fructans of only $20 \%$. This is even lower than the $30 \%$ sugar reduction level that is generally required in Europe to bear the claim "reduced sugar" [24].

In addition to the acute postprandial effects highlighted in the present publication, inulin-type fructans have also been shown to have long-term benefits for blood glucose management. Recent studies indicate lower fasting blood glucose levels and a reduction of the postprandial blood glucose response also after continued intake of inulin-type fructans $[25,26,27]$.

Inulin and oligofructose offer technological benefits (such as, e.g., a good stability during food processes), improved organoleptic features (no aftertaste, better mouthfeel), and enhanced nutritional properties that are linked for instance to the higher fibre content or a reduced sugar content of the final product [9]. Hence, the replacement of glycaemic carbohydrates with inulintype fructans from chicory provides two major advantages to the consumer: an attenuated postprandial blood glucose response and at the same time a higher intake of dietary fibre.

Daily intake of dietary fibre is below the recommended intake levels all over the world [28] with important consequences for public health such as for instance an increased risk of coronary heart disease, hypertension, adiposity, and metabolic dysfunctions including type 2 diabetes [29]. Hence, fortifying foods with added dietary fibre is an important strategy for increasing fibre intakes while maintaining calories at the recommended levels [28, 29]. The application of chicory root fibre, i.e., inulin and oligofructose, at the expense of glycaemic carbohydrates in foods and drinks could thus contribute to fill in the fibre gap among the population [30]. 


\section{Conclusions}

In conclusion, the current findings show that inulin-type fructans from chicory (inulin, oligofructose) can be used in foods and drinks by partially replacing glycaemic carbohydrates, leading to a significant reduction in postprandial blood glucose response without disproportionately increasing the insulin response. The extent to which postprandial glycaemia is reduced depends on the percentage of glycaemic carbohydrates replaced by inulin or oligofructose from chicory. A significant reduction of the postprandial blood glucose response has been demonstrated starting from $20 \%$ of the glycaemic sugars replaced with chicory inulin-type fructans in a final food product. Based on the current findings, further research into the longer term effects of replacing the conventional food and drink products with such sugar-reduced versions is warranted.

\section{Acknowledgements}

We thank all participants for their time and effort. Furthermore, we would like to thank the product development department of CRDS Südzucker for the development and production of test samples (yogurt drinks, fruit jellies).

Author contribution statement All authors were involved in the development of the study protocol. H. Lightowler and S. Thondre were responsible for data collection, data analysis, and interpretation of the data. A Holz and S Theis wrote the initial draft of the manuscript. All the authors read, commented upon, and made a significant contribution to the submitted manuscript.

Compliance with ethical standards

Conflict of interest Both studies were funded by BENEO GmbH (a member of the Südzucker Group), Cosucra-Groupe Warcoing S.A. and Sensus B.V. The funding companies reserve the exclusive right to use the results and data for regulatory proceedings and health claim requests. The yogurt drinks and fruit jellies were specially developed for this study and produced by BENEO/CRDS Südzucker. A. Holz and S. Theis are employees of BENEO/Südzucker Group.

\section{References}

1. Blaak EE, Antoine JM, Benton D et al (2012) Impact of postprandial glycaemia on health and prevention of disease. Obes Rev 13(10):923-984 
2. Ludwig D (2002) The glycaemic index: physiological mechanisms relating to obesity, diabetes, and cardiovascular disease. JAMA 287(18):2414-2423

3. Cavalot F, Petrelli A, Traversa M et al (2006) Postprandial blood glucose is a stronger predictor of cardiovascular events than fasting blood glucose in type 2 diabetes mellitus, especially in women: lessons from the San Luigi Gonzaga Diabetes Study. J Clin Endocrinol Metab 91(3):813-819

4. Rendell MS, Jovanovic L (2006) Targeting postprandial hyperglycemia. Metab Clin Exp 55(9):1263-1281

5. Woerle HJ, Neumann C, Zschau S et al (2007) Impact of fasting and postprandial glycemia on overall glycemic control in type 2 diabetes: importance of postprandial glycemia to achieve target HbA1c levels. Diabetes Res Clin Pract 77(2):280-285

6. Roberfroid M, Slavin J (2000) Nondigestible oligosaccharides. Crit Rev Food Sci Nutr 40(6):461-480

7. Ellegård L, Andersson H, Bosaeus I (1997) Inulin and oligofructose do not influence the absorption of cholesterol, or the excretion of cholesterol, $\mathrm{Ca}$, $\mathrm{Mg}, \mathrm{Zn}, \mathrm{Fe}$, or bile acids but increases energy excretion in ileostomy subjects. Eur J Clin Nutr 51(1):1-5

8. Schaafsma G, Slavin L (2015) Significance of inulin fructans in the human diet. Comp Rev Food Sci Food Safety 14(1):37-47

9. Franck A (2002) Technological functionality of inulin and oligofructose. Br J Nutr 87(Supp1 2):S287-S291

10. Meyer D (2007) Dietary fibre: components and functions: inulin for product development of low GI products to support weight management. Wageningen Academic Publishers, Roosendaal

11. Grysman A, Carlson T, Wolever T (2008) Effects of sucromalt on postprandial responses in human subjects. Eur J Clin Nutr 62(12):1364-1371

12. Tarini J, Wolever T (2010) The fermentable fibre inulin increases postprandial serum short-chain fatty acids and reduced free-fatty acids and ghrelin in healthy subjects. Appl Physiol Nutr Metab 35(1):9-16 
13. EFSA NDA Panel (2014) Scientific opinion on the substantiation of a health claim related to non-digestible carbohydrates and a reduction of postprandial glycaemic responses pursuant to Article 13(5) of Regulation (EC) No 1924/2006. EFSA J 12(1):3513

14. European Commission-Commission Implementing Regulation (EU) 2016/854 authorising certain health claims made on foods, other than those referring to the reduction of disease risk and to children's development and health and amending Regulation (EU) No 432/2012

15. ISO food products-determination of the glycaemic index (GI) and recommendation for food classification (26642:2010)

16. EFSA NDA Panel (2012) Guidance on the scientific requirements for health claims related to appetite ratings, weight management, and blood glucose concentrations. EFSA J 10(3):2604

17. Hätönen KA, Simila E, Virtamo JR et al (2006) Methodologic considerations in the measurement of glycemic index: glycemic response to rye bread, oatmeal porridge, and mashed potatoe. Am J Clin Nutr 84(5):1055-1061

18. Siahanidou T, Margeli A, Kappis A et al (2011) Circluating vasfatin levels in healthy preterm infants are independently associated with highdensity lipoprotein cholesterol levels and dietary long-chain polyunsaturated fatty acids. Metabolism 60(3):389-393

19. Atkinson F, Foster-Powell K, Brand-Miller J (2008) International tables of glycemic index and glycemic load values. Diabetes Care 31(12):22812283

20. Brynes AE, Edwards CM, Ghatei MA et al (2003) A randomised fourintervention crossover study investigating the effect of carbohydrates on daytime profiles of insulin, glucose, non-esterified fatty acids and triacylglycerols in middle-aged men. Br J Nutr 89(2):207-218

21. Wolever TM, Jenkins DJ, Vuksan V et al (1992) Beneficial effect of a low glycaemic index diet in type 2 diabetes. Diabet Med 9(5):451-458

22. Venn B, Green T (2007) Glycemic index and glycemic load: measurement issues and their effect on diet-disease relationships. Eur J Clin Nutr 61 (Supp1 1):S122-S131 
23. Aziz A, Dumais L, Barber J (2013) Health Canada's evaluation of the use of glycemic index claims on food labels. Am J Clin Nutr 98(2):269-274

24. European Commission-Regulation (EC) No. 1924/2006 of the European Parliament and of the council of 20 December 2006 on nutrition and health claims made on foods

25. Kellow N, Coughlan M, Reid C (2014) Metabolic benefits of dietary prebiotics in human subjects: a systematic review of randomised controlled trials. Br J Nutr 111(7):1147-1161

26. Dehghan P, Pourghassem Gargari B, Asghari Jafar-abadi M (2014) Oligofructose-enriched inulin improves some inflammatory markers and metabolic endotoxemia in women with type 2 diabetes mellitus: a randomized controlled clinical trial. Nutrition 30(4):418-423

27. Dehghan P, Pourghassem Gargari B, Asghari Jafar-abadi M et al (2014) Inulin controls inflammation and metabolic endotoxemia in women with type 2 diabetes mellitus: a randomized-controlled clinical trial. Int J Food Sci Nutr 65(1):117-123

28. Jones JM (2014) CODEX-aligned dietary fiber definitions help to bridge the 'fiber gap'. Nutr J 13:34

29. Clemens R, Kranz S, Mobley AR et al (2012) Filling America's fiber intake gap: summary of a roundtable to probe realistic solutions with a focus on grain-based foods. J Nutr 142(7):1390S-1401S

30. Deehan EC, Walter J (2016) The fiber gap and the disappearing gut microbiome: implications for human nutrition. Trends Endocrinol Metab 27(5):239-242 